\title{
An Exploratory Investigation of Consumers' Perceptions of the Risks of Online Shopping in Jordan
}

\author{
Mahmaod Ibrahim Al-Rawad ${ }^{1}$, Adel Al Khattab ${ }^{1}$, Zaid Ibrahim Al-Shqairat ${ }^{1}$, Tamara Altabieri Krishan ${ }^{2}$ \& \\ Mohammad Haroon Jarrar ${ }^{1}$ \\ ${ }^{1}$ College of Business Administration and Economics, Al-Hussein Bin Talal University, Ma'an, Jordan \\ ${ }^{2}$ Al-Balqa' Applied University, Maan, Jordan \\ Correspondence: Mahmaod Al-rawad, College of Business Administration and Economics, Al-Hussein bin Talal \\ University, Ma'an, Jordan. Tel: 962-79-020-6960. E-mail: m_rawd@yahoo.com
}

Received: October 28, 2014 Accepted: December 3, 2014 Online Published: January 26, 2015

doi:10.5539/ijms.v7n1p157 URL: http://dx.doi.org/10.5539/ijms.v7n1p157

\begin{abstract}
Purpose: The current research seeks to identify the most relevant dimensions of risk perceived by online shopping customers in Jordan, by identifying risk dimensions cited in the literature and testing empirically their relative importance to such customers.
\end{abstract}

Design: A self-administered questionnaire was completed by a random stratified sample of adults. The response rate of $62.5 \%$ was adequate to ensure that the survey results were accurate, useful, and representative of the target population. The data were analyzed using parametric statistics including means analysis, factor analysis, and the t-test.

Findings: The participants perceived functional and financial risks most strongly, while social risk was the lowest ranked dimension. Furthermore, previous experience and future intention to use were significantly correlated with the strength of participants' perceptions of each category of online shopping risks.

Limitations/Implications: A practical implication of this study is the possibility that the findings will provide insight regarding consumers' perceptions of online shopping risks, and help businesses to pinpoint the risks of greatest concern to customers.

Originality: This study is one of the first to provide important information on the perception of online shopping risks by Jordanian customers.

Keywords: Jordan, perceived risk, perceived risk dimensions, online shopping, consumers' risk perception

\section{Introduction}

Over the past thirty years, there has been a dramatic increase in research into the adoption and acceptance of technology, resulting in the development and publication of several models and theories, including the Technology Adoption Model (TAM) (Davis, 1989) and its upgraded version TAM2 (Venkatesh \& Davis, 2000), Diffusion of Innovation (DOI) (Rogers, 1962), and Task-Technology Fit (Goodhue \& Thompson, 1995). Using these theories and models, researchers have sought to determine the factors that affect the intention of individuals and organizations to adopt and use technology, by proposing a variety of factors and testing their effects on users' intentions. They have introduced a range of factors and determinants that may affect intention to use technology, including perceived ease of use (PEOU), perceived usefulness, compatibility, complexity, triability, observability, and relative advantage. However, the growing use of e-commerce and online payment services has heightened the need to examine the riskiness of the environment in which these services operate. Consequently, other factors have been proposed and tested for their role in individuals' actual use and intention to use such technology, including risk perception, trust, security, and privacy (e.g., Al-Rawabdeh, Zeglat, \& Al-Zawahreh, 2012; Mcknight, Choudhuryb, \& Kacmarc, 2002; Joubert \& Van Belle, 2013).

Accordingly, recent attention has been given to the perception of risk by online shopping customers and its role in forming consumers' attitudes to online shopping (e.g., Zheng, Favier, Huang, \& Coat, 2012; Dai, Forsythe, \& Kwon, 2014; Samadi \& Yaghoob-Nejadi, 2009; Zhang, Tan, Xu, \& Tan, 2012; Almousa, 2014; Alam \& Yasin, 2010). As a result, researchers within the general field of technology adoption and acceptance have succeed in 
establishing the effect of perceived risk on consumers' willingness to use online services in general and online shopping in particular (e.g., Dai et al., 2014; Zheng et al., 2012; Zhang et al., 2012; Almousa, 2014; Samadi \& Yaghoob-Nejadi, 2009; Alam \& Yasin, 2010; Featherman \& Pavlou, 2003; Jarvenpaa, Tractinsky, \& Saarinen, 1999). Perceived risk has thus been implicitly and explicitly incorporated into the extant online adoption and acceptance literature, and found to be a significant determinant of the adoption of new technologies (Zhang et al., 2012; Bélanger \& Carter; 2008; Dimitrova \& Chen, 2006).

However, risk perception is frequently overlooked or given less detailed attention than other variables; for instance, much of the current literature on the adoption and acceptance of online shopping treats risk perception as a one-dimensional construct (Pires, Stanton, \& Eckford, 2004) or sometimes as an external factor that affects intention through other factors such as trust and PEOU (e.g., Gefen, Pavlou, Warkentin, \& Gregory, 2002; Horst, Kuttschreuter, \& Gutteling, 2007; Featherman \& Pavlou, 2003). There are nevertheless some researchers (e.g., Almousa, 2014; Dai et al., 2014; Zheng et al. 2012) who have argued that risk perception should be treated as a multidimensional construct in order to gain a better understanding of its role in forming individuals' intention to adopt online shopping, and to identify the types of risks associated with this activity (Almousa, 2014). Such researchers have proposed several dimensions of the perceived risk concept that could provide a better understanding of online shopping risks. For instance, Dai et al. (2014) consider three dimensions of perceived risk (Product risk, Financial risk, and Privacy risk), while Zheng et al. (2012) identify five dimensions: product or performance, financial, social, psychological, and physical risks.

Unsurprisingly, there is (as yet) no agreed set of dimensions for perceived risk in the online shopping literature, or even on how many there should be; in addition to the two above sets, other authors have proposed four, six, and eight dimensions. Therefore, the current research seeks to identify the most relevant dimensions of perceived risk associated with online shopping from the customers' perspective, by identifying risk dimensions cited in the literature and empirically testing their relative importance to customers in the context of Jordan. It also seeks to determine whether perceived risk differs among respondents according to gender, previous experience, and future intention to use. A practical implication of this study is the possibility that the findings will provide some insight regarding consumers' perception of risk and thus help businesses to pinpoint the risks of greatest concern to their customers.

The remainder of this paper is in four parts. The first reviews the literature on risk perception among online shoppers, the second sets out the research method, and the third reports the results. The paper concludes with a discussion, a consideration of the implications and limitations of the study, and suggestions for future research.

\section{Literature Review}

\subsection{Perceived Risk}

Bauer (1960) was the first to introduce the concept of perceived risk to the consumer behavior literature. According to him, perceived risk could be seen as uncertainty regarding any possible negative outcomes of commencing an action; thus, buying a product or services could be seen as a risk-taking behavior. Following this proposition, researchers within the consumer behavior field began to acknowledge the role that perceived risk plays in consumers' decision making (Jacoby \& Kaplan, 1972; Peter \& Tarpey, 1975). This view was extended to researchers in the field of information systems (IS), in their attempts to understand factors affecting intention to use new technologies (e.g., Jarvenpaa et al., 1999; Van Den Poel \& Leunis, 1999; Bhatnagar \& Ghose, 2004; Doolin, Dillons, Thompson, \& Corner, 2005; Drennan, Mort, \& Previte, 2006; Kuhlmeier \& Knight, 2005; Slyke, Belanger, \& Comunale, 2004; Farzianpour, Pishdar, Shakib, \& Toloun, 2014). Accordingly, most of the current literature recognizes a significant relation between users' willingness to adopt new technologies and risk perception, in areas such as online shopping, e-services, and e-banking.

Although extensive research has been carried out into the role that perceived risk plays in consumers' willingness to engage with new technologies such as online shopping, the methods by which perceived risk has been investigated provide little detailed insight and fail to identify the types of risks that are of most concern to individuals. This may at least partially be ascribed to the fact that much of the previous IS research has treated risk perception as a one-dimensional construct (e.g., Gefen et al., 2002; Bélanger \& Carter, 2005; Curran \& Meuter, 2005; Kesharwani \& Bisht, 2012). However, some IS researchers, recognizing the role that perceived risk plays in the adoption and acceptance of new technologies, have begun to explore different approaches to perceived risk, which is increasingly viewed as a multidimensional concept by technology adoption scholars (e.g., Zheng et al., 2012; Farzianpour et al., 2014; Farzianpour, Dargahi, Hosseini, \& Hosseini, 2011; Zhang et al., 2012; Almousa, 2014; Dai et al., 2014). 


\subsection{Dimensions of Perceived Risk}

Cox (1967) was the first to introduce a multidimensional measurement of perceived risk. According to him, perceived risk can be categorized into two main dimensions: performance and psychosocial risks. He subdivides performance risks into economic, temporal, and effort risks, while the psychosocial dimension comprises the psychological and social aspects of an event. A broader perspective is proposed by Cunningham (1967), who argues that perceived risk should be divided into six dimensions: performance, financial, opportunity, safety, social, and psychological. Cunningham also highlights the need for a practical measurement of consumers' perceived risk. Thus, he proposes two measurement components: the likelihood that a negative event will take place and the severity of that event's consequences. According to this model, a consumer's overall perceived risk can be obtained by multiplying the probability of an event by its negative consequences for all proposed dimensions.

The approaches to perceived risk of Cox and Cunningham have motivated other scholars to investigate various other dimensions and measurements. For instance, Jacoby \& Kaplan (1972) propose the measurement of perceived risk on five dimensions: social, psychological, physical, performance, and financial risk. However, rather than using Cunningham's probability and consequences approach, they propose a Likert scale with a single statement for each dimension to measure consumers' perceptions of risk. Similarly, Peter \& Tarpey (1975) investigated three decision-making strategies and their ability to explain brand preference. While testing the Minimization of Perceived Risk strategy using Cunningham's probability and consequences model, they define perceived risk operationally in terms of six dimensions: social, psychological, physical, performance, financial, and time risk.

Other researchers have attempted to reform the previously proposed dimensions of perceived risk into general risk types. For instance, Brooker (1984) applied the dimensions proposed by Jacoby \& Kaplan (1972) (social, psychological, physical, performance, and financial risk) to consumers' decisions, to test their validity and to determine whether they could be grouped into general risk types. Having established the validity of the scale using coefficient alpha, he used factor analysis with varimax rotation to test its internal consistency and factor structure. He found that all five dimensions used in his study could be grouped under two main factors, labeled Non-personal Risk (financial, performance, and physical) and Personal Risk (psychological, social, and time-loss), which together explained $60.7 \%$ of the variance in consumers' decisions to buy the products studied.

By default, early studies of perceived risks focused on risks related to traditional marketplaces and purchasing situations (Zheng et al., 2012). However, with the appearance of new channels such as catalogue, telephone and, most importantly, online shopping, there arose an urgent need to include other types of risks reflecting the uncertainty associated with these channels (Zheng et al., 2012; Noort, Kerkhof, \& Fennis, 2007). Consequently, IS researchers began to explore and propose new dimensions of perceived risk, including delivery risk, privacy risk, security risk and after-sale risk, using different approaches, such as integrating perceived risks with existing adoption and acceptance theories and models used in IS studies, including TAM and DOI (e.g., Almousa, 2014, Dai et al., 2014; Lu et al., 2005; Zhang et al., 2012; Farzianpour et al., 2014). Other researchers have also studied directly the role of perceived risk in technology acceptance (e.g., Zheng et al., 2012).

Table 1 lists the dimensions of perceived risk most commonly used in the marketing and IS literature. Most have been shown by numerous studies to have negative effects on users' intention to engage in various technologies and activities, including online banking, e-services, e-government, mobile banking, mobile commerce, and online shopping. The aims of the current research are to identify empirically the relative importance of these dimensions to online shopping, from the customers' perspective, and to establish whether the importance of these dimensions differs among respondents based on their demographic variables and online shopping experience. 
Table 1. Perceived risk dimensions

\begin{tabular}{|c|c|c|}
\hline Risks Dimension & Definition & Previous studies \\
\hline Physical & $\begin{array}{l}\text { A potential threat to an individual's safety, physical } \\
\text { health, and wellbeing }\end{array}$ & $\begin{array}{l}\text { Mitchell \& Greatorex (1993); Zheng et al. (2012); } \\
\text { Zhang et al. ( 2012); Dai et al. (2014); Lu et al. (2005) }\end{array}$ \\
\hline Functional & $\begin{array}{l}\text { The probability that a product might not perform as } \\
\text { expected }\end{array}$ & $\begin{array}{l}\text { Mitchell \& Greatorex (1993); Zheng et al. (2012); } \\
\text { Zhang et al. (2012); Almousa (2014); Lu et al. (2005) }\end{array}$ \\
\hline Social & $\begin{array}{l}\text { Concerned with an individual's ego and the effect that } \\
\text { a purchase will have on the opinions of reference } \\
\text { groups }\end{array}$ & $\begin{array}{l}\text { Mitchell \& Greatorex (1993); Farzianpour et al. (2014); } \\
\text { Zheng et al. (2012); Zhang et al. (2012); Almousa } \\
\text { (2014) }\end{array}$ \\
\hline Time-loss & $\begin{array}{l}\text { The possibility that a purchase will take too long or } \\
\text { waste too much time }\end{array}$ & $\begin{array}{l}\text { Farzianpour et al. ( 2014); Zheng et al. (2012); Zhang et } \\
\text { al. (2012); Almousa (2014) }\end{array}$ \\
\hline Financial & $\begin{array}{l}\text { The possibility that the product will not be worth the } \\
\text { financial price and would have been available cheaper } \\
\text { elsewhere }\end{array}$ & Zheng et al. (2012); Dai et al. ( 2014); Almousa (2014) \\
\hline Opportunity cost & $\begin{array}{l}\text { The possibility that the "the best alternative is not } \\
\text { chosen" }\end{array}$ & Lu, Hsu, \& Hsu (2005) \\
\hline Information & $\begin{array}{l}\text { The possibility that the individual is operating in an } \\
\text { environment of asymmetric information }\end{array}$ & Lu et al. (2005) \\
\hline Privacy & $\begin{array}{l}\text { Potential loss of control over personal information, } \\
\text { when this is used without permission. }\end{array}$ & $\begin{array}{l}\text { Farzianpour et al. (2011; 2014); Zheng et al. (2012); } \\
\text { Zhang et al. (2012); Dai et al. (2014); Almousa (2014) }\end{array}$ \\
\hline Delivery & $\begin{array}{l}\text { Not receiving the product on time, long delivery time, } \\
\text { or product being damaged during delivery. }\end{array}$ & Zheng et al. (2012); Zhang et al. (2012) \\
\hline After-sale & $\begin{array}{l}\text { Potential loss of after-sales service associated with } \\
\text { product problems, commercial disputes, and service } \\
\text { guarantee. }\end{array}$ & Zhang et al. (2012) \\
\hline
\end{tabular}

\section{Method}

The main data collection method was a self-administered questionnaire, based on designs reported in the literature and validated as described below. There were two main sections, the first containing questions on respondents' demographic characteristics and on their experience and usage of the internet and online shopping. The second section contained 36 statements with which respondents were asked to indicate their level of agreement on a Likert-type scale from 1 (strongly disagree) to 5 (strongly agree). These statements, which were developed to test the importance of particular types of online risks, were validated in prior research, adapted, and translated into Arabic for use in the current research.

\subsection{Sample and Data Collection}

The study sample mainly comprised individuals between 20 and 60 years old. The sample frame represented individuals relatively likely to be familiar with internet use and who could be potential online shoppers. In order to reduce sampling error, the researchers used a random stratified sampling technique to select a sufficient number of subjects from these strata: males and females, workers and non-workers or students.

Table 2. Descriptive statistics of respondents' characteristics

\begin{tabular}{|c|c|c|c|c|c|}
\hline Gender & Frequency & $\%$ & Online shopping experience & Frequency & $\%$ \\
\hline Male & 330 & 52.8 & Yes & 226 & 36.2 \\
\hline Female & 295 & 47.2 & No & 399 & 63.8 \\
\hline Age (years) & Frequency & $\%$ & Internet usage (years) & Frequency & $\%$ \\
\hline 22 or less & 168 & 26.88 & Less than 2 & 132 & 21.1 \\
\hline $23-30$ & 338 & 54.08 & $2-5$ & 242 & 38.7 \\
\hline $31-50$ & 107 & 17.12 & $5-8$ & 116 & 18.6 \\
\hline 51 and over & 12 & 1.92 & 8 and over & 135 & 21.6 \\
\hline Education & Frequency & $\%$ & Internet shopping frequency & Frequency & $\%$ \\
\hline High school & 135 & 21.6 & Once & 87 & 13.9 \\
\hline University degree & 436 & 69.76 & $2-5$ times & 83 & 13.3 \\
\hline \multirow[t]{2}{*}{ Postgraduate degree } & 54 & 8.64 & $6-10$ times & 35 & 5.6 \\
\hline & & & 11 times or more & 31 & 5.0 \\
\hline
\end{tabular}


One thousand questionnaires were distributed among university students and local government employees in Jordan. A total of 657 were completed and returned, giving a response rate of $65.7 \%$. Of these, 32 were incomplete, however, reducing the final response to $62.5 \%$. Table 2 provides a brief description of the questionnaire respondents, showing that slightly more than half were male, that most were aged between 20 and 50 years, and that about a third had some previous experience of online shopping.

\section{Results and Discussion}

In order to be able to draw conclusions from the current research and generalize its findings, the validity and reliability of the measures were established using the most common statistical techniques in social science, including principle component analysis (PCA) and the Cronbach's alpha test. The data were then analyzed in line with the research objectives using several statistical techniques, including mean analysis and the t-test. This section begins by reporting the results of the validity and reliability tests, and then discusses in some detail the ranking of the perceived risk dimensions.

\subsection{Measurement Validity and Reliability}

The component statements of the questionnaire were adapted from previous studies and translated into Arabic; therefore, it was necessary to establish scale validity and reliability in order to generalize the research findings. According to Hair, Anderson, Tatham, \& Black (1998), validity is the degree to which an instrument measures the attributes or constructs it intends to measure. Its measurement validity is established when the convergent and discriminant validity of the items used are found to be satisfactory (Chau, 1996).

To test the validity of the research instrument, PCA with varimax rotation was carried out on all items. This requires that each variable clearly differentiate itself in the factor loadings; otherwise it should be removed. Standardized factor loadings greater than 0.6 are considered high, whereas items below the cut-off limit for loading of 0.4 are removed from the analysis (Hair et al., 1998).

The loading values for the items in the research instrument are listed in Table 3, which shows that they exceeded the cut-off level of 0.4 in all cases. In addition, all of the study items were loaded on the respective factors or components. Hence, the convergent and discriminant validity of the instrument were established (Hu, Chau, Liu, \& Tam, 1999). However, four cases of cross-loading were reported and then removed from further analysis; these were used to measure social risk, physical risk, opportunity risk and functional risk. The risks studied were found to explain $58.7 \%$ of the total variance. The Kaiser-Meyer-Olkin measure of sampling adequacy ( 0.89$)$ was above the recommended 0.5 level.

Cronbach's alpha was calculated as a test of the instrument's reliability. Table 3 shows that the results were positive: the scale items shared a common fabric and all reached the cut-off $\alpha$ value of 0.60 accepted in the social sciences (e.g., Malhotra, Birks, \& Wills, 2006).

Table 3. Loading and Cronbach's alpha test results for perceived risk dimensions

\begin{tabular}{llll}
\hline Risk & Statement & Loading & Alpha \\
\hline \multirow{4}{*}{ Physical } & Using the product will not cause danger to my health or safety. & 0.694 & 0.760 \\
& The loss of online shopping would put pressure on my heart. & 0.690 & 0.752 \\
\hline \multirow{5}{*}{ Functional } & Buying counterfeit products can damage my health. & 0.697 & 0.826 \\
& I may purchase something by accident. & 0.669 & 0.702 \\
\hline \multirow{5}{*}{ Social } & I may buy counterfeit products while online shopping. & 0.772 \\
& The actual quality of the goods does not match its description. & 0.791 & 0.824 \\
\hline \multirow{5}{*}{ Time-loss } & Online shopping may affect the image of people around me. & 0.623 & 0.725 \\
& Online products may not be recognized by relatives or friends. & 0.632 \\
& Online shopping may make others reduce their evaluation of me. & 0.660 \\
& Too complicated to place orders. & Difficult to find appropriate websites. & 0.567 \\
& Sellers may not deliver on time and I may have to wait for my goods. & 0.640 \\
& Communicating with the seller and the service may require a lot of time. & 0.678 \\
\hline
\end{tabular}




\begin{tabular}{|c|c|c|c|}
\hline \multirow[t]{3}{*}{ Financial } & I may find that I can buy the same product at a lower price from somewhere. & 0.801 & 0.767 \\
\hline & An additional fee will be charged for delivery service. & 0.686 & \\
\hline & I might be overcharged & 0.740 & \\
\hline \multirow{3}{*}{ Opportunity cost } & Online product may not be the best choice. & 0.651 & 0.655 \\
\hline & Price comparison needs some effort. & 0.690 & \\
\hline & There is a limited range of products and services. & 0.760 & \\
\hline \multirow{3}{*}{ Information } & The website information is not reliable. & 0.699 & 0.729 \\
\hline & Finding information on the site needs time and effort. & 0.584 & \\
\hline & Looking for information on the site need some experience. & 0.690 & \\
\hline \multirow{3}{*}{ Privacy } & My personal information may not be kept safe. & 0.711 & 0.682 \\
\hline & My email address may be abused by others. & 0.630 & \\
\hline & My personal information may be disclosed to others companies. & 0.622 & \\
\hline \multirow{3}{*}{ Delivery } & An additional fee will be charged for express delivery. & 0.562 & 0.688 \\
\hline & After shopping, goods are easily lost. & 0.636 & \\
\hline & Express delivery may be sent to the wrong place. & 0.663 & \\
\hline \multirow{3}{*}{ After-sale } & If I have problem with a product, it will be hard to contact the seller. & 0.694 & 0.720 \\
\hline & It is difficult to solve commercial disputes in online shopping. & 0.687 & \\
\hline & Products purchased online may lack an after-sales service guarantee. & 0.516 & \\
\hline
\end{tabular}

\subsection{Ranking of Perceived Risk Dimensions}

Table 4 ranks the dimensions of perceived online shopping risks in descending order, by the percentage of respondents who agreed (slightly or strongly) with the corresponding statements. Among the ten dimensions, our selected sample perceived functional risk most strongly, with $54.5 \%$ agreement. Financial risk was ranked second, with the slightly lower score of $54.2 \%$, closely followed by physical risk. There was again a very small difference in score between security and information risk, ranked fourth and fifth. The dimension ranked tenth, social risk, scored only half as much as time-loss, ranked ninth, indicating that online shoppers were much less concerned with social risks than with the other dimensions.

Table 4. Dimensions of perceived online shopping risks, ranked by percentage of respondents who agreed or strongly agreed

\begin{tabular}{llll}
\hline Type of Risk & Number of Items & $\%$ & Ranking \\
\hline Functional & 340 & 54.4 & 1 \\
Financial & 339 & 54.2 & 2 \\
Physical & 334 & 53.4 & 3 \\
Security & 309 & 49.4 & 4 \\
Information & 308 & 49.3 & 5 \\
Opportunity Cost & 301 & 48.2 & 6 \\
After-sale & 287 & 45.9 & 7 \\
Delivery & 279 & 44.6 & 8 \\
Time-loss & 257 & 41.1 & 9 \\
Social & 127 & 20.3 & 9 \\
\hline
\end{tabular}

These results are to some extent consistent with those of earlier studies of online shoppers in different counties, such as Zheng et al. (2012) in China and Ko, Jung, Kim \& Shim (2004) in the USA and Korea. For instance, the Chinese, American and Korean samples all ranked social risk as the second lowest risk, while functional risk was ranked highest by the American and Korean shoppers and second highest by the Chinese respondents. The American and Korean samples also ranked financial risk second highest, as did the Jordanian respondents in the present study. Some other rankings differed significantly among the studies, however; for example, physical 
risk was ranked third highest in the present study but third lowest by the Chinese shoppers and lowest of all by the American and Korean participants.

\subsection{Group Comparison}

The second objective of the current research was to test for any differences in perceived risk dimensions among different groups of respondents, such as by gender or experience of online shopping. An independent-samples t-test was conducted to compare the means of three sets of groups: male / female, online shopping experience / no previous experience, respondents who intended / did not intend to use online shopping services. The results are presented in Table 5.

Table 5. Means and standard deviations on dimensions of perceived online shopping risk by gender, online shopping experience and intention to use

\begin{tabular}{|c|c|c|c|c|c|c|c|c|}
\hline \multirow[t]{2}{*}{ Risk } & & \multirow[t]{2}{*}{ All respondents } & \multicolumn{2}{|c|}{ Gender } & \multicolumn{2}{|c|}{ Online shopping exp } & \multicolumn{2}{|c|}{ Intention to use } \\
\hline & & & Male & Female & Exp & No exp & Yes & No \\
\hline \multirow[t]{3}{*}{ Physical } & Mean & 3.43 & 3.36 & 3.51 & 3.20 & $3.56 *$ & 3.34 & $3.58 *$ \\
\hline & SD & 1.392 & 1.375 & 1.409 & 1.376 & 1.386 & 1.386 & 1.393 \\
\hline & $\mathrm{N}$ & 625 & 330 & 295 & 226 & 399 & 394 & 231 \\
\hline \multirow[t]{3}{*}{ Functional } & Mean & 3.43 & 3.37 & 3.50 & 3.19 & $3.57 * *$ & 3.29 & $3.67 *$ \\
\hline & SD & 1.351 & 1.299 & 1.407 & 1.251 & 1.387 & 1.361 & 1.304 \\
\hline & $\mathrm{N}$ & 625 & 330 & 295 & 226 & 399 & 394 & 231 \\
\hline \multirow[t]{3}{*}{ Social } & Mean & 2.76 & 2.85 & 2.66 & 2.61 & $2.85 *$ & 2.65 & $2.95 *$ \\
\hline & SD & 1.191 & 1.191 & 1.184 & 1.177 & 1.191 & 1.111 & 1.296 \\
\hline & $\mathrm{N}$ & 625 & 330 & 295 & 226 & 399 & 394 & 231 \\
\hline \multirow[t]{3}{*}{ Time-loss } & Mean & 3.02 & 2.98 & 3.06 & 2.87 & $3.10 *$ & 2.87 & $3.27 * *$ \\
\hline & SD & 1.209 & 1.198 & 1.223 & 1.130 & 1.246 & 1.190 & 1.204 \\
\hline & $\mathrm{N}$ & 625 & 330 & 295 & 226 & 399 & 394 & 231 \\
\hline \multirow[t]{3}{*}{ Financial } & Mean & 3.41 & 3.42 & 3.40 & 3.07 & $3.60 * *$ & 3.27 & $3.65 * *$ \\
\hline & SD & 1.289 & 1.270 & 1.313 & 1.263 & 1.266 & 1.281 & 1.269 \\
\hline & $\mathrm{N}$ & 625 & 330 & 295 & 226 & 399 & 394 & 231 \\
\hline \multirow[t]{3}{*}{ Opportunity cost } & Mean & 3.28 & 3.25 & 3.31 & 3.16 & $3.35 *$ & 3.17 & $3.47 *$ \\
\hline & SD & 1.244 & 1.235 & 1.255 & 1.216 & 1.256 & 1.220 & 1.264 \\
\hline & $\mathrm{N}$ & 625 & 330 & 295 & 226 & 399 & 394 & 231 \\
\hline \multirow[t]{3}{*}{ Information } & Mean & 3.28 & 3.33 & 3.24 & 3.04 & $3.42 * *$ & 3.14 & $3.53 * *$ \\
\hline & SD & 1.286 & 1.234 & 1.342 & 1.216 & 1.305 & 1.267 & 1.281 \\
\hline & $\mathrm{N}$ & 625 & 330 & 295 & 226 & 399 & 394 & 231 \\
\hline \multirow[t]{3}{*}{ Delivery } & Mean & 3.20 & 3.11 & 3.31 & 3.01 & $3.31 *$ & 3.08 & $3.40 *$ \\
\hline & SD & 1.234 & 1.233 & 1.230 & 1.162 & 1.262 & 1.181 & 1.298 \\
\hline & $\mathrm{N}$ & 625 & 330 & 295 & 226 & 399 & 394 & 231 \\
\hline \multirow[t]{3}{*}{ After-sale } & Mean & 3.27 & 3.28 & 3.26 & 3.16 & $3.34 *$ & 3.18 & $3.44 *$ \\
\hline & SD & 1.225 & 1.233 & 1.228 & 1.187 & 1.243 & 1.230 & 1.200 \\
\hline & $\mathrm{N}$ & 625 & 330 & 295 & 226 & 399 & 394 & 231 \\
\hline \multirow[t]{3}{*}{ Security } & Mean & 3.38 & 3.36 & 3.41 & 3.08 & $3.56 * *$ & 3.19 & $3.71 * *$ \\
\hline & SD & 1.347 & 1.334 & 1.362 & 1.303 & 1.342 & 1.372 & 1.240 \\
\hline & $\mathrm{N}$ & 625 & 330 & 295 & 226 & 399 & 394 & 231 \\
\hline
\end{tabular}

$* * \mathrm{p}<0.001, * \mathrm{p}<0.05$

Table 5 shows that there were no significant differences in mean scores between males and females for any dimension of perceived risk, whereas the t-test revealed significant differences between the groups with and without online shopping experience on all dimensions. Specifically, respondents who had online shopping experience tended to rate the risks associated with online shopping less strongly than those with no previous experience. Similarly, there were significant differences in mean risk perception scores on all dimensions between respondents who expressed their intention to use online shopping in the future and those who did not, with the latter group perceiving the risks as greater.

Few published studies have examined the relationships of previous online experience or intention to use with users' perceptions of risk; thus, comparisons with the findings of this study will be limited by several factors, including risk dimensions used and types of services or products studied. However, from such comparisons as are possible, it appears that the findings of the current study are not consistent with those of previous research. 
For instance, Pires et al. (2004) found no significant relationship between previous online shopping experience and perceived risk among Australian internet users. A possible explanation for this is that Australian online shopping facilities and infrastructure differ significantly from those provided in Jordan.

\section{Conclusion}

The purposes of the current study were to identify the most relevant risks of online shopping from the perspective of customers in Jordan and to determine whether their perceptions of risk differed according to their gender, previous experience, and intention to use. Empirical data were collected from 625 respondents using a self-administered questionnaire whose design was based on the work of several researchers in the fields of IS and marketing. The validity and reliability of the research instrument were established, then the data were analyzed to rank the ten different types of online risks under investigation.

Functional risk was ranked as the predominant dimension of online risk by the percentage of respondents (54\%) who agreed with the corresponding questionnaire items, followed very closely by financial and physical risks, all of which appeared to have the same importance for online shoppers in Jordan. Security and information risks were ranked fourth and fifth, again with very little difference between them. By far the largest gap in perception was between time-loss risk in ninth rank (41\%) and social risk in last place (20\%). Thus, social risk appears to be much less important to Jordanian online shoppers than any other category of perceived risk.

In regard to the second objective, the evidence from this study suggests that both genders perceived online risk at the same level, whereas there were significant differences on all risk dimensions between respondents who had previous online shopping experience and those who had no experience at all. The former tended to perceive all risks less strongly than the latter, and the same differences emerged on all risk dimensions between those who intended to use online shopping in the future and those who did not.

These empirical findings provide a new understanding of online shopping risk perceptions in Jordan. They could help practitioners to minimize the effects of those risks by adopting the appropriate communication strategies and providing potential customers with sufficient information, promises and guarantees to reduce the uncertainty surrounding each type of risk. This work also contributes to existing knowledge of online shopping by providing insight regarding the online risk perceptions of users in an emerging country. These findings offer researchers valuable information for use in future studies comparing countries or cultures.

Finally, a number of important limitations need to be considered. First, the current research did not measure risk dimensions associated with a specific product or service, such as clothing, music, or electrical goods. It would be interesting to conduct such work in future. Nor did the current research seek to establish a causal relationship between perceived risk and intention to use, as it was exploratory in nature. Future studies could take this work further by seeking to measure the strength and polarity of associations between risk dimensions and customers' intention to engage in online activities.

\section{References}

Alam, S., \& Yasin, M. (2010). What factors influence online brand trust: evidence from online tickets buyers in Malaysia. Journal of Theoretical and Applied Electronic Commerce Research, 5(3), 78-89. http://dx.doi.org/10.4067/S0718-18762010000300008.

Almousa, M. (2014). The Influence of Risk Perception in Online Purchasing Behavior: Examination of an Early-Stage Online Market. International Review of Management and Business Research, 3(2), 779-787.

Al-Rawabdeh, W., Zeglat, D., \& Al-Zawahreh, A. (2012). The Importance of Trust and Security Issues in E-Commerce Adoption in the Arab World. European Journal of Economics, Finance and Administrative Sciences, (52).

Bauer, R. A. (1967). Consumer behavior as risk-taking. In R. S. Hancock (Eds.), Risk-taking and information-handling in consumer behavior (pp. 389-398). Harvard University Press: Boston.

Bélanger, F., \& Carter, L. (2005). Trust and risk in e-government adoption. In Proceedings of the Eleventh Americas Conference on Information Systems. Omaha, NE, USA.

Bélanger, F., \& Carter, L. (2008). Trust and risk in e-government adoption. Journal of Strategic Information Systems, 17(2), 195-179.

Bhatnagar, A., \& Ghose, S. (2004). Segmenting Consumers Based on the Benefits and Risks of Internet Shopping. Journal of Business Research, 57, 1352-1360. 
Brooker, G. (1984). An assessment of an expanded measure of perceived risk. Advances in Consumer Research, 11(1), 439-441.

Chau, K. (1996). An Empirical Assessment of a Modified Technology Acceptance Model. Journal of Management Information Systems, 13(2), 185-204.

Cox, D. F. (1967). The major dimensions of perceived risk. In R. S. Hancock (Ed.), Risk-taking and information-handling in consumer behavior (pp. 389-398). Harvard University Press: Boston.

Curran, J., \& Meuter, M. (2005). Self-Service Technology Adoption: Comparing Three Technologies. Journal of Services Marketing, 19(2), 102-113. http://dx.doi.org/10.1108/08876040510591411

Dai, B., Forsythe, S., \& Kwon, W. (204). The Impact of Online Shopping Experience on Risk Perceptions and Online Purchase Intentions: Does Product Category Matter? Journal of Electronic Commerce Research, 15(1), 13-24.

Davis, F. D. (1989). Perceived usefulness, perceived ease of use and user acceptance of information technology. MIS Quarterly, 13(3), 319-339. http://dx.doi.org/10.2307/249008

Dimitrova, D. V., \& Chen, C., Y. (2006). Profiling the adopters of E-Government information and services: The influence of psychological characteristics, civic mindedness, and information channels. Social Science Computer Review, 24(2), 172-188. http://dx.doi.org/10.1177/0894439305281517

Doolin, B., S., Dillons, S., Thompson, F., \& Corner, L. (2005). Perceived Risk, the Internet Shopping Experience and Online Purchasing behavior: A New Zealand Perspective. Journal of Global Information Management, 13(2), 66-88. http://dx.doi.org/10.4018/jgim.2005040104

Drennan, J., Mort, S., \& Previte, S. (2006). Privacy, Risk Perception, and Expert Online Behavior: An Exploratory Study of Household End Users. Journal of Organizational and End User Computing, 18(1), 1-22. http://dx.doi.org/10.4018/joeuc.2006010101

Farzianpour, H., Dargahi, S., Hosseini, S., \& Hosseini, S. (2011). Program evaluation of health care management: Is it adjusted for students needs? American Journal of Economics and Business Administration, 3(2), 420-424. http://dx.doi.org/10.3844/ajebasp.2011.420.424

Farzianpour, H., Pishdar, M., Shakib, M., \& Toloun, M. (2014). Consumers' perceived Risk and its Effect on Adoption of online banking services. American Journal of Applied Sciences, 11(1). http://dx.doi:10.3844/ajassp.2014.47.56

Featherman, S., \& Pavlou, A. (2003). Predicting E-services adoption: A perceived risk facets perspective. International Journal of Human-Computer Studies, 59, 451-474. http://dx.doi.org/10.1016/S1071-5819(03)00111-3

Gefen, D., Pavlou, P., Warkentin, M., \& Rose, G. (2002). Egovernment adoption. AMCIS 2002 Proceedings.

Goodhue, D. L., \& Thompson, R. L. (1995). Task-technology fit and individual performance. MIS Quarterly, 19(2), 213-236. http://dx.doi.org/10.2307/249689

Hair, F., Anderson, E., Tatham, L. Black, C. (1998). Multivariate data analysis (7th ed.). Englewood Cliffs, NJ: Prentice-Hall.

Horst, M., Kuttschreuter, M., \& Gutteling, J. M. (2007). Perceived usefulness, personal experiences, risk perception and trust as determinants of adoption of e-government services in the Netherlands. Computers in Human Behavior, 23(4), 1838-1852. http://dx.doi.org/10.1016/j.chb.2005.11.003

Hu, P., Chau, K., Liu, R., \& Tam, Y. (1999). Examining the technology acceptance model using physician acceptance of telemedicine technology. Journal of Management Information Systems, 16(2), 91-112.

Jacoby, J., \& Kaplan, B. (1972). The components of perceived risk. In the Third Annual Conference of the Association for Consumer Research.

Jarvenpaa, S. L., Tractinsky, N., \& Saarinen, L. (1999). Consumer Trust in an Internet Store: A Cross-Cultural Validation. Journal of Computer-Mediated Communication, 5(2).

Joubert, J., \& Van Belle, J. (2012). The Role of Trust and Risk in Mobile Commerce Adoption within South Africa. International Journal of Business, Humanities and Technology, 3(2), 27-38.

Kesharwani, A., \& Bisht, S. (2012). The impact of trust and perceived risk on internet banking adoption in India: An extension of technology acceptance model. International Journal of Bank Marketing, 30(4), 303-332. http://dx.doi.org/10.1108/02652321211236923 
Ko, H., Jung, J., Kim J., \& Shim, W. (2004). Cross-cultural differences in perceived risk of online shopping. Journal of Interactive Advertising, 4(2), 20-29. http://dx.doi.org/10.1080/15252019.2004.10722084

Kuhlmeier, D., \& Knight, G. (2005). Antecedents to Internet-Based Purchasing: A Multinational Study. International Marketing Review, 22(4), 460-473. http://dx.doi.org/10.1108/02651330510608460

Lu, H., Hsu, C., \& Hsu, H. (2005). An empirical study of the effect of perceived risk upon intention to use online applications. Information Management and Computer Security, 13(2), 106-120. http://dx.doi.org/10.1108/09685220510589299

Malhotra, K., Birks, D., \& Wills, P. (2012). Marketing research: an applied approach (4th ed.). Prentice Hall.

Mcknight, D. H., Choudhuryb, V., \& Kacmarc, C. (2002). The impact of initial consumer trust on intentions to transact with a web site: a trust building model. Journal of Strategic Information Systems, 11(3), 297-323. http://dx.doi.org/10.1016/S0963-8687(02)00020-3

Mitchell, W., \& Greatorex, M. (1993). Risk perception and reduction in the purchase of consumer services. The service Industry Journal, 13(4), 179-200. http://dx.doi.org/10.1080/02642069300000068

Noort, V., Kerkhof, P., \& Fennis, M. (2007). The Persuasiveness of Online Safety Cues: The Impact of Prevention Focus Compatibility of Web Content on Consumers' Risk Perceptions, Attitudes, and Intentions. Journal of Interactive Marketing, 22(4), 58-72.

Peter, P., \& Tarpey, X. (1975). A Comprehensive Analysis of Three Consumer Decision Strategies. Journal of Consumer Research, 2, 29-37.

Pires, G., Stanton, J., \& Eckford, A. (2004). Influences on the Perceived Risk of Purchasing Online. Journal of Consumer Behaviour, 4(2), 118-131. http://dx.doi.org/10.1002/cb.163

Rogers, E. M. (1995). Diffusion of Innovations. New York: Free Press.

Samadi, M., \& Yaghoob-Najadi, A. (2009). A survey of the effect of consumers' perceived risk on purchase intention in E-shopping. Business Intelligence Journal, 2(2), 261-275.

Slyke, V., Belanger, F., \& Comunale, D. (2004). Factors Influencing the Adoption of Web-Based Shopping: The Impact of Trust. Database for Advances in Information Systems, 35(2), 32-49. http://dx.doi.org/10.1145/1007965.1007969

Van Den Poel, D., \& Leunis, J. (1999). Consumer acceptance of the Internet as a channel of distribution. Journal of Business Research, 45(3), 249-256.

Venkatesh, V., \& Davis, F. D. (2000). A theoretical extension of the technology acceptance model: Four $\begin{array}{lllll}\text { longitudinal field } & \text { studies. }\end{array}$ http://dx.doi.org/10.1287/mnsc.46.2.186.11926

Zhang, L., Tan, W., Xu, Y., \& Tan, G. (2012). Dimensions of Perceived Risk and Their Influence on Consumers Purchasing Behavior in the Overall Process of B2C. CISME, 2(7), 8-14. http://dx.doi.org/10.1007/978-3-642-24823-8_1

Zheng, L., Favier, M., Huang, P., \& Coat, F. (2012). Chinese Consumer Perceived Risk and Risk Relievers in E-shopping for Clothing. Journal of Electronic Commerce Research, 13(3), 255-274.

\section{Copyrights}

Copyright for this article is retained by the author(s), with first publication rights granted to the journal.

This is an open-access article distributed under the terms and conditions of the Creative Commons Attribution license (http://creativecommons.org/licenses/by/3.0/). 